\title{
Human endogenous retroviruses and cancer prevention: evidence and prospects
}

\author{
Luca Cegolon ${ }^{1,2^{*}}$, Cristiano Salata' ${ }^{1}$ Elisabete Weiderpass ${ }^{3,4,5,6}$, Paolo Vineis ${ }^{2,7}$, Giorgio Palù ${ }^{1}$ \\ and Giuseppe Mastrangelo ${ }^{1}$
}

\begin{abstract}
Background: Cancer is a significant and growing problem worldwide. While this increase may, in part, be attributed to increasing longevity, improved case notifications and risk-enhancing lifestyle (such as smoking, diet and obesity), hygiene-related factors resulting in immuno-regulatory failure may also play a major role and call for a revision of vaccination strategies to protect against a range of cancers in addition to infections.

Discussion: Human endogenous retroviruses (HERVs) are a significant component of a wider family of retroelements that constitutes part of the human genome. They were originated by the integration of exogenous retroviruses into the human genome millions of years ago. HERVs are estimated to comprise about $8 \%$ of human DNA and are ubiquitous in somatic and germinal tissues.

Physiologic and pathologic processes are influenced by some biologically active HERV families. HERV antigens are only expressed at low levels by the host, but in circumstances of inappropriate control their genes may initiate or maintain pathological processes. Although the precise mechanism leading to abnormal HERVs gene expression has yet to be clearly elucidated, environmental factors seem to be involved by influencing the human immune system. HERV-K expression has been detected in different types of tumors.

Among the various human endogenous retroviral families, the $K$ series was the latest acquired by the human species. Probably because of its relatively recent origin, the HERV-K is the most complete and biologically active family.

The abnormal expression of HERV-K seemingly triggers pathological processes leading to melanoma onset, but also contributes to the morphological and functional cellular modifications implicated in melanoma maintenance and progression.

The HERV-K-MEL antigen is encoded by a pseudo-gene incorporated in the HERV-K env-gene. HERV-K-MEL is significantly expressed in the majority of dysplastic and normal naevi, as well as other tumors like sarcoma, lymphoma, bladder and breast cancer. An amino acid sequence similar to HERV-K-MEL, recognized to cause a significant protective effect against melanoma, is shared by the antigenic determinants expressed by some vaccines such as BCG, vaccinia virus and the yellow fever virus.

HERV-K are also reactivated in the majority of human breast cancers. Monoclonal and single-chain antibodies against the HERV-K Env protein recently proved capable of blocking the proliferation of human breast cancer cells in vitro, inhibiting tumor growth in mice bearing xenograft tumors.

(Continued on next page)
\end{abstract}

\footnotetext{
*Correspondence: I.cegolon@gmail.com

'Department of Molecular Medicine, Padua University, Padua, Italy ${ }^{2}$ Imperial College London, School of Public Health, S. Mary's Campus, London, UK

Full list of author information is available at the end of the article
}

\section{Biomed Central}

(c) 2013 Cegolon et al.; licensee BioMed Central Ltd. This is an Open Access article distributed under the terms of the Creative Commons Attribution License (http://creativecommons.org/licenses/by/2.0), which permits unrestricted use, distribution, and reproduction in any medium, provided the original work is properly cited. 
(Continued from previous page)

Summary: A recent epidemiological study provided provisional evidence of how melanoma risk could possibly be reduced if the yellow fever virus vaccine (YFV) were received at least 10 years before, possibly preventing tumor initiation rather than culling melanoma cells already compromised. Further research is recommended to confirm the temporal pattern of this protection and eliminate/attenuate the potential role of relevant confounders as socio-economic status and other vaccinations.

It appears also appropriate to examine the potential protective effect of YFV against other malignancies expressing high levels of HERV-K antigens, namely breast cancer, sarcoma, lymphoma and bladder cancer.

Tumor immune-therapy, as described for the monoclonal antibodies against breast cancer, is indeed considered more complex and less advantageous than immune-prevention. Cellular immunity possibly triggered by vaccines as for YFV might also be involved in anti-cancer response, in addition to humoral immunity.

Keywords: HERV-K, Cancer prevention, Melanoma, Breast cancer, Ovarian cancer, BCG, Vaccinia, Yellow fever virus vaccine, Epidemiology

\section{Background}

Cancer is a significant and growing problem worldwide $[1,2]$. In the United Kingdom, for example, $42 \%$ of people who died in 2008 had a diagnosis of cancer sometime in their life, and tumors were the cause of death in $64 \%$ of these patients [3].

The improvement of survival observed in the past 20 years is associated with a marked increase in the average treatment cost for most common cancers $[4,5]$. The new targeted cancer treatments are expected to raise even more abruptly in the next future [6], especially in developed countries such the US where the population older than 65 is expected to almost double in 2030 [7].

Although improved case notifications, increasing longevity and risk-enhancing lifestyle (such as smoking, diet and obesity) have to be taken into account, the burden of cancer may in part be attributed also to hygienerelated factors resulting in immuno-regulatory failure $[8,9]$. The latter call for a revision of vaccination strategies to protect against a range of cancers in addition to infections.

\section{Discussion}

\section{Human endogenous retroviruses}

The human genome contains around 400,000 genetic loci [10], evolved as a result of past infection by many different kinds of retroviruses. Approximately $45 \%$ of human genome is actually composed of or derived from virus-like transposon-related elements $[11,12]$.

Germ cell infections by exogenous retro-viruses occurred millions of years ago and led to the stable maintenance of human endogenous retroviruses (HERVs) into the human genome. The integration of HERVs into the host cell happens within the context of their replication cycle $[13,14]$. HERVs are estimated to comprise about $8 \%$ of human DNA $[15,16]$ and two hypotheses have been suggested to justify their persistence in the human genome during evolution. According to the parasitic theory HERVs were neutral and their elimination was rather difficult [17-21]. Conversely, the symbiotic theory sees them retained by positive selection, provided their function was relevant to maintain certain vital conditions [22]. However, the two hypotheses are not mutually exclusive, as after the initial integration, subsequent random mutations of the parasitic viral RNA of HERVs led to the synthesis of important human proteins, enabling retroviruses to persist in the human DNA as symbiotic. Zeyl [23] recently reviewed the significance of symbiotic DNA in eukaryotes.

Unlike typical viruses, HERVs are not infectious $[15,24]$, but they can be transmitted vertically as proviruses in a Mendelian fashion [25]; furthermore as a consequence of multiple mutations and deletions, they are defective and therefore unable to retro-transpose [26].

\section{HERV expression}

After integrating into the host DNA, HERVs can produce hundreds of copies of themselves and newly integrate throughout the human genome. HERV genes gag, pol and env are flanked by genetic regulatory sequences named Long Terminal Repeats (LTRs), used by HERV to insert their genetic sequences into the host DNA and able to regulate both retroviral and sometimes functional human genes.

HERVs generally become non replication competent by recombinational deletion between the two LTRs and/ or by random mutations occurring while the host genome is undergoing DNA replication. However, complete or incomplete gene products can be either directly coded by HERV genes env or gag or result from recombinational mechanisms [27]. Physiologic and pathologic processes are influenced by some biologically active HERV families through direct RNA viral transcripts or mutations generated by retro-transposition [28]. As 
mentioned earlier HERVs indeed code for fundamental human proteins and have been highly involved in the intra-uterine development of the fetus as well as in the evolution of the human species [29,30]. The env region of three HERVs (ERV-3, HERV-W and HERV-FRD) is crucial to form the placental syncytiotrophoblast, and HERV-FRD seems also to contribute in down-regulation of human immunity against the fetus and prevent its rejection [31,32].

HERV antigens are only expressed at low levels by the host, but in circumstances of inappropriate control the expression of HERV genes may initiate or maintain pathological processes [33]. According to microarray analysis, HERV expression appears to be positively influenced by the exposure to exogenous (e.g chemicals, UV radiations $[34,35])$ and endogenous (e.g. cytokines, hormones $[34,36,37])$ stimuli.

Although the precise mechanism leading to abnormal HERVs gene expression has to be further elucidated, environmental factors seem to be involved by influencing the human immune system [38], and hypo-methylation of the relevant retroviral genes appears a key factor $[39,40]$.

\section{The HERV-K family}

HERVs are classified in more than 22 different families [15,41-44] depending on their sequence identity and partly on the similarity of their primer binding sites to host tRNAs $[15,44,45]$.

Among the various human endogenous retroviral families, the $\mathrm{K}$ series was the latest acquired by the human species, between three and six million years ago [46]. Probably because of this relatively recent origin, the HERV-K is the most complete and biologically active family, being composed of retro-elements showing polymorphic integration in the human genome $[15,43,47,48]$.

HERV-K is the only known retroviral family that has retained functional full-length open reading frames (ORF) coding for structural and enzymatic proteins $[15,49,50]$ and appears capable to induce the generation of replicating viral components $[29,47,51]$.

HERV-K encoding loci are thought to be transcriptionally silent in normal cells, becoming active after malignant transformation, as found in germ cell tumors [52]. Activation of HERV-K may initiate or maintain carcinogenesis.

HERV-K expression was detected in different types of tumors and Hill's causal criteria for epidemiology have been recently adapted to assess virus-cancer associations [53]):

- consistency of the association. Transcripts of HERVs have been detected by many independent investigators in different tumors: breast cancer [25,54-60], ovarian cancer [61], lymphoma [54], melanoma $[25,62,63]$, germ line tumors $[51,60,64]$, haematological neoplasms $[65,66]$, sarcoma [25], bladder and prostate cancer [25], primary skin tumours and lymphatic metastases [50,55];

- strength of the association. HERV genes are rarely expressed in normal tissues [25,67] and adjacent tissues of breast [58] and other types of cancers [68];

- temporality. Environmental factors - both exogenous (chemicals [35], UV radiation, [34,69,70], smoking [71], viruses [72]) and endogenous (estrogen [36], and cytokines [37]) - facilitate HERV expression;

- biological plausibility. HERV proteins reduce expression of glutathione peroxidase, thus increasing the levels of reactive oxygen species with subsequent cumulative cell damage [73];

- experimental evidence. Vaccinating against a peptide from a mouse endogenous retrovirus was shown to prevent, though not to cure, established melanoma in mice [74].

\section{HERV-K and Melanoma}

The abnormal expression of HERV-K seemingly triggers the pathological processes leading to melanoma onset, but also contributes to the morphological and functional cellular modifications implicated in melanoma maintenance and progression [62]. Figure 1 shows the presumed cascade of events between HERV-K expression and melanoma initiation. The molecular mimicry of HERV-K transcript with Oxygen Responsive Element Binding Protein (OREBP) decreases the expression of glutathione peroxidase and increases the toxicity from free radicals leading to higher risk of cancer [38].

Conversely to benign melanocytic lesions, specimen from patients with primary or metastatic melanoma as well as melanoma biopsy-derived cell lines were reported to express HERV-K antigens such as the viral reverse transcriptase (RT) [50,55]. Down-regulation (by RNA interference) and pharmacological inhibition of RT resulted in a reduced proliferation, induced morphological differentiation and reprogrammed gene expression in melanoma cells. Discontinuation of anti-RT treatment reversed the latter figures, suggesting a possible epigenetic level of control by RT [75].

Down-regulation of HERV-K led to rejection of melanoma cells in immune-competent mice [76] and decreased cancerogenic capacity of melanoma cells inoculated into nude mice [77]. It has been hypothesized that HERV-K expression contributes to evade immune-surveillance in immune-competent mice, thus promoting the growth of transformed cells and stimulating tumour progression $[63,77]$.

An immune-dominant epitope on the Env protein is recognized by antibodies from sera of patients with 


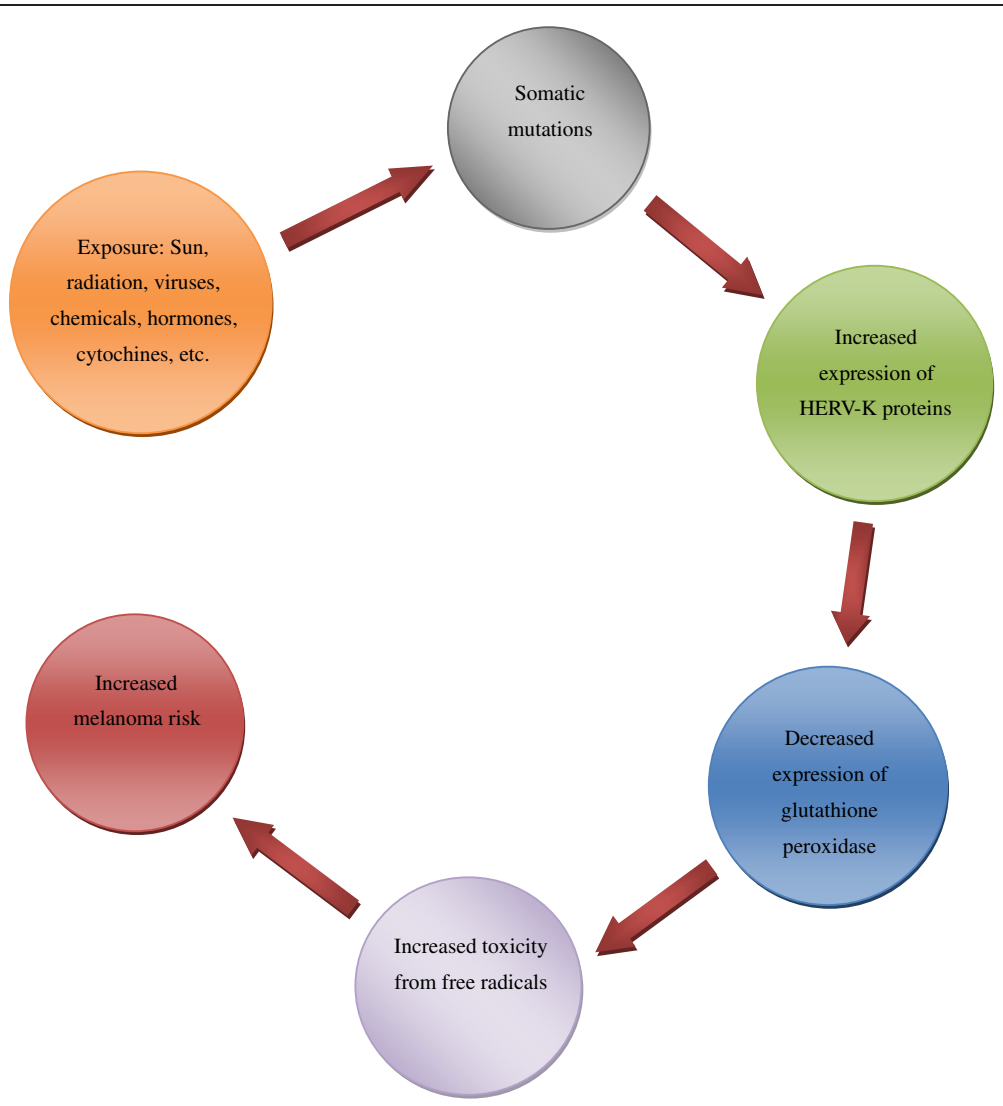

Figure 1 Cascade of events due to homology sequence between the HERV-K Env protein and OREBP [38].

melanoma. The prevalence of antibodies against the immune-dominant epitope of the HERV-K Env protein was significantly higher in sera from 81 melanoma patients with American Joint Committee on Cancer (AJCC) stage I-IV disease, compared with 95 control sera from healthy individuals [78]. In another study antibodies against HERV-K gag and env transcripts have been observed in $16 \%(=51 / 312)$ sera of melanoma patients but not in 70 healthy controls [79]. Furthermore antibodies specific for a HERV-K trans-membrane envelope protein were reportedly found in $22 \%$ sera from patients with metastatic melanoma $(\mathrm{N}=60)$, but again their prevalence in sera from 20 normal blood donors and patients with alopecia was nil [55]. There is evidence that the antibody response against HERV-K proteins in AJCC stages I-III melanoma patients is associated with poorer survival, and has thus been proposed as an additional prognostic factor [79].

However, the presentation of HERV-K epitopes on the surface of affected cells appeared also to represent the "Achilles' heel" in the pathological changes induced by HERV-K [8]. These epitopes could indeed potentially serve as targets for immunity response aiming at repairing or eliminating the compromised cells.
Similarly to antiviral vaccines now used to prevent cervical cancer (anti-HPV vaccine) or hepatocellular carcinoma (anti-hepatitis B vaccine) preventive vaccines against usually non-expressed retroviral antigens may stimulate long lasting CD8+ T lymphocytic response in an otherwise vulnerable host that could then become able to eradicate early malignancies expressing these retroviral antigens [58].

Nearly $85 \%$ of malignant melanocytes express an antigen called HERV-K-MEL, a product of a pseudo-gene incorporated in the HERV-K env gene $[25,80,81]$. The HERV-K-MEL antigen, already previously defined as a marker of melanoma risk, is not present in normal tissues, but is significantly expressed in the majority of dysplastic and normal naevi, as well as other tumors like sarcoma, lymphoma, bladder, breast and ovarian cancer [25].

The FEBrile Infections and Melanoma (FEBIM) multicentre case-control study provided evidence how the Bacillus of Calmette Guerin (BCG) and vaccinia virus vaccination given in early childhood or acute infectious diseases acquired later in life were associated with a lesser melanoma risk [81]. This evidence was further examined and confirmed in another multi-centre case- 
control study conducted on 603 incident cases of malignant melanoma and 627 population controls (Table 1) [82].

A protein bearing a high homology sequence of amino acids with the antigen HERV-K-MEL is expressed by BCG and vaccinia virus vaccine (Table 2). The yellow fever virus vaccine (YFV) was also found to express an antigen with a strict homology sequence of amino acids with HERV-K-MEL (Table 2) [38].

Sera from four Rhesus macaques before and four weeks after being administered with YFV were incubated with melanoma cells from two randomly selected patients: immune reactivity was observed at indirect immune-fluorescence in most apes post vaccination [Hunsmann \& Krone 2005. Vaccination against malignant melanoma. European Patent EP1586330A1].

This suggests that YFV might confer a protection against melanoma, by molecular mimicry (Figure 2).

To assess this protective effect, a cohort study $(28,306$ subjects vaccinated with YFV) and a case-control study nested in the cohort (37 melanoma cases vs. 151 tumours not expressing HERV-K-MEL) was recently performed in North-Eastern Italy [83]. The time elapsed since YFV up to end of follow up (TSV) was split into the following year intervals: $0-4 ; 5-9 ; 10+$. In the case control study contrasting melanoma with tumors non-expressing HERV-K-MEL, the Odds Ratios (OR) for the above mentioned time bands adjusted for age and sex were 1.00, 0.96, (95\% CI: 0.43-2.14) and 0.26 (95\% CI: 0.07-0.96). The risk of melanoma was therefore reduced if YFV had been received at least 10 years before, as a result of prevention of tumor initiation rather than culling of already compromised melanoma cells [83].

Hodges Vasquez et al. [84] recently conducted a casecontrol study on 7,010 members of the US military to test the association between YFV and melanoma risk. Total cases of melanoma in this cohort were 638 diagnosed from 1999 to 2009 and each of them was contrasted with 10 healthy controls from active duty military service members. The study concluded that no significant association between YFV 17D and melanoma risk was found. However the maximum TSV was only 11.5 years and controls were presumably selected among

Table 1 Case-control study (FEBIM-1): Combined effect of infections and vaccinations on the risk of melanoma; Odds ratios (95\% confidence interval) for melanoma risk, adjusted for study centre, gender, age, skin phenotype, freckling index, number of naevi and solar burns [82]

\begin{tabular}{lll}
\hline & \multicolumn{2}{l}{ Number of severe infections } \\
\cline { 2 - 3 } & $\mathbf{0}$ & $\mathbf{1}$ \\
\hline No vaccine & 1.0 & $0.37(0.10-1.42)$ \\
BCG or Vaccinia & $0.57(0.33-0-96)$ & $0.29(0.15-0.57)$ \\
BCG and Vaccinia & $0.40(0.23-0.68)$ & $0.33(0.17-0.65)$ \\
\hline
\end{tabular}

Table 2 Comparison between amino acid sequence of HERV-K-MEL and proteins from different viruses [38]

\begin{tabular}{lcccccccccc}
\hline HERV-K-Mel & $M$ & $L$ & $A$ & $V$ & - & I & S & $C$ & $A$ & $V$ \\
\hline BCG & $\mathrm{L}$ & $*$ & $*$ & $*$ & DV & $V$ & $P$ & I & $*$ & $*$ \\
\hline Vaccinia virus & $S$ & $*$ & $*$ & $*$ & $V$ & $*$ & $A$ & $*$ & $*$ & \\
\hline Yellow fever virus & $S$ & $*$ & $*$ & $*$ & - & - & $*$ & $S$ & $*$ & $*$
\end{tabular}

$A=$ Alanine; L: Leucine; $V=$ Valine; $I=$ Isoleucine; $S=$ Serine; $M=$ Methionine; $\mathrm{C}=$ Cisteine; $\mathrm{P}=$ Proline; $\mathrm{D}=$ Aspartic Acid; $\mathrm{G}=$ Glycine; ${ }^{*}=$ Identical amino acids; ${ }_{-}=$Missing amino acid.

healthy subjects. Selecting controls among individuals with malignancies other than melanoma from the same cohort of vaccinees (as done in the above Italian study) might influence the strength of the association, as study subjects would be a better choice. If the interaction between YFV and HERV-K-MEL prevents melanoma, healthy individuals could not be accepted as controls because some of them could be "cases of melanoma prevented by YFV" rather than simply subjects without disease. Prevention of melanoma could occur frequently because numerous infectious agents produce homologous epitopes capable of generating cross-reactive immunity.

The presumed causal structure of the relationships between YFV, HERV-K, and melanoma can be conveyed in a directed acyclic graph (DAG) [85]. DAG \#1 of Figure 3 relates to tumors expressing HERV-K-MEL. It can be seen that the cause (symbol A) is YFV; the confounders (B) include recreational solar exposure and high social class; the outcome $(\mathrm{C})$ is cancer; and the mediators are expression of the HERV-K-MEL (D) and the immune response (E). The confounders may increase the use of YFV, affect expression of the HERV-K-MEL gene (and of other HERV-K genes) coding for putative oncogenic proteins, thus increasing the risk of cancer. YFV may induce a cross-reactive immune response that could decrease the expression of HERV-K genes and destroy or repair the cancer or its precursor cells by means of $\mathrm{CD}^{+}$T-lymphocytes. Since the corresponding paths are both open, YFV can be postulated to increase cancer through confounders (top path) as well to decrease it through immune response (bottom path). DAG \#2 of Figure 3 relates to tumors not expressing HERV-K-MEL. It can be seen that YFV may be postulated to only increase cancer risk through confounders as the specific immune response is unlikely to affect these tumors.

\section{HERV-K and ovarian cancer}

It was reported that multiple HERVs are simultaneously expressed in ovarian cancers [61]. Antibodies against HERV-K Env, HERV-E Env o ERV3 proteins have been detected in sera of patients affected by ovarian cancer, but not in healthy controls [61]. The presence of these antibodies provides indirect evidence of how HERV-K 


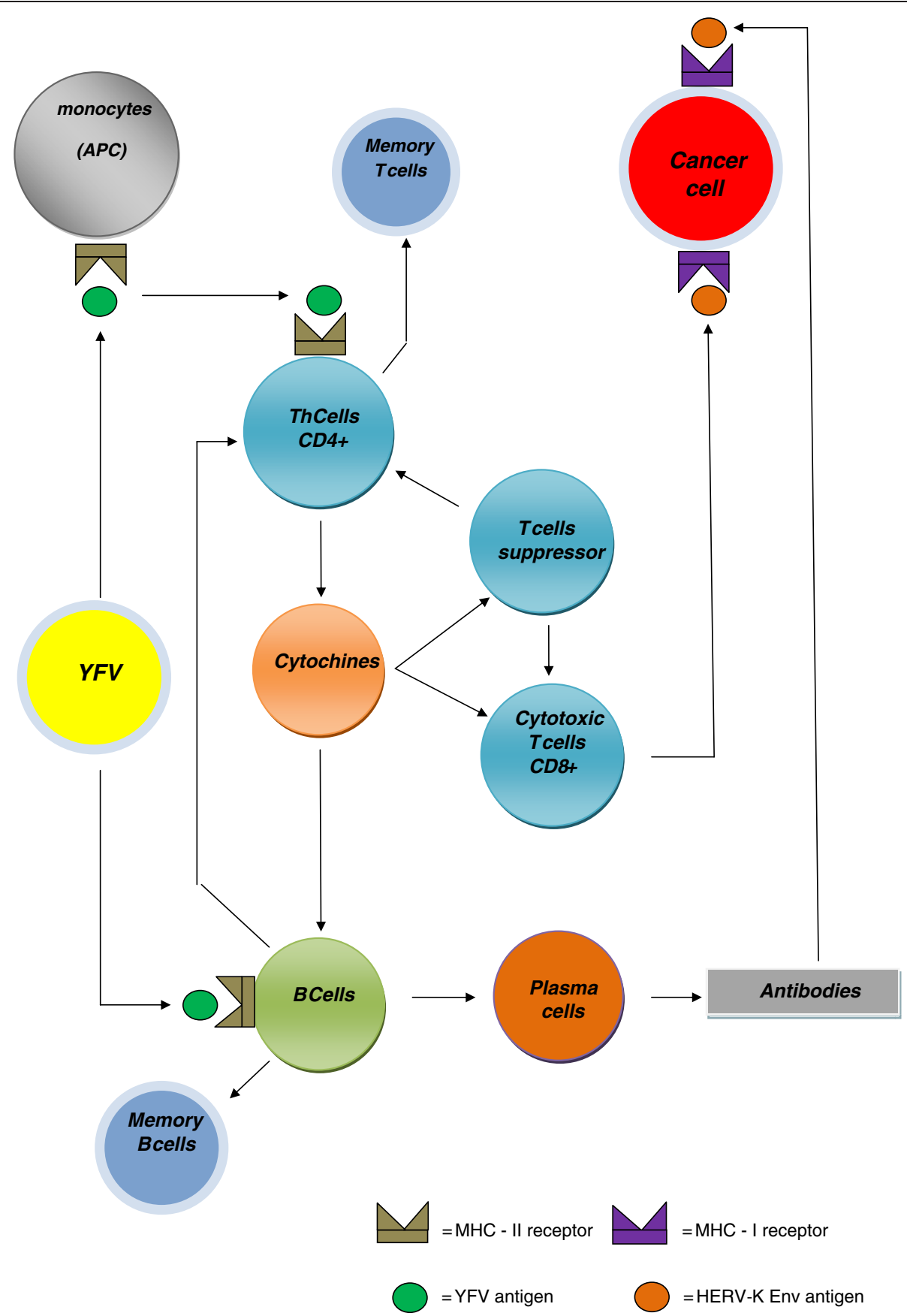

Figure 2 Molecular mimicry and immunological response possibly triggered by the yellow fever virus vaccine (YFV), leading to cancer prevention. $\mathrm{APC}=$ Antigen presenting cells.

proteins might be immunogenic and act as tumor associated antigens.

The production of specific HERV-K antibodies indicates a lack of immunity tolerance and might signify that HERV-K expression during ontogenesis did not happen for ovarian cells, as proposed for melanoma [55]. Patients affected by ovarian cancer seem thus able to mount an immune response against specific HERVs, and immunotherapy against HERV-K proteins might be effective against ovarian cancer. In this regard it is important to note that HERV-K proteins are expressed in $90 \%$ of epithelial ovarian tumors, whereas their expression is nil in normal tissues or epithelial tissues from benign ovarian cancers [61].

Activation of HERV-K expression in ovarian cancer might happen in response to a transcriptional factor 
1. Tumors expressing HERV-K

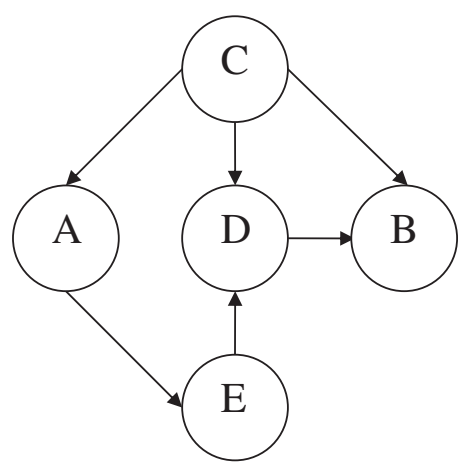

2. Tumors not expressing HERV-K

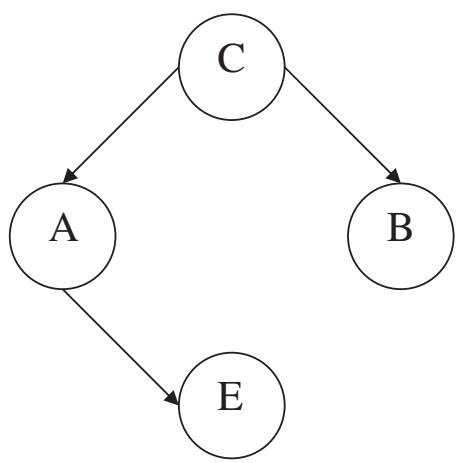

Symbols: "A" = cause (YFV); "B" = outcome (cancer); "C" = confounders (recreational solar exposure and high social class); "D" and "E" = mediators (HERV-K antigen and immune response).

Figure 3 Directed acyclic graph (DAG) displaying the causal structure of the relationships between yellow fever vaccine (YFV), HERV-K, and cancer.

detected specifically in malignant epithelial cells of ovarian cancers [86-88]. This activation might be the result of hypo-methylation of HERV-K genomic DNA during tumor transformation and progression [61]. Retrotransposons have been reported as potential targets of hypomethylation during cellular transformation [89]. An enhanced HERV-K expression has been reported as a result of DNA hypo-methylation in urothelial cancer [90] and germ line tumours [91]. A similar mechanism could occur also for ovarian cancer.

Assessment of HERV-K expression may therefore represent a new screening tool for ovarian cancer in the future, and served as target for detection, diagnosis and treatment of this neoplasm [61].

\section{HERV-K and breast cancer}

Breast cancer is the leading cancer type and the second cause of cancer death among women of industrialized countries [92]. About $10 \%$ of breast cancer is attributable to genetic predisposition [93,94], with approximately $30 \%$ familial cases due to BRCA- 1 or BRCA-2 genes mutations [95].

Earlier studies have suggested that protection from breast cancer is associated with early exposure to some common viruses, whereas exposure later in life increases the risk [96].

Breast cancer cell lines and tissues were found to express HERV-K env transcripts, whilst non-malignant breast tissues did not [93]. HERV-K expression was significantly higher in most breast cancer tissues than in normal breast tissues and a statistical correlation between estro-progestin stimuli and HERV-K env transcripts in breast cancer cells was reported by various authors $[59,97,98]$. In particular, HERV-K RT was found to be expressed in different human breast cancer cell lines but not in normal human breast tissues [98]. The exact role of HERV-K proteins in breast cancerogenesis is still obscure [98], but HERV-K env may contribute to cancer proliferation [57].

Expression of HERV-K env was recently detected in $66 \%(=148 / 223)$ human breast cancers inoculated into mice, and lymphnode metastatis were more likely to occur in HERV-K positive tumours [57]. Similarly to melanoma, HERV-K RT expression and humoral response against HERV-K antigens was identified as a novel marker and prognostic factor in disease free patients for breast cancer $[57,79,98]$.

Monoclonal and single-chain antibodies against the HERV-K Env antigen proved capable of blocking proliferation of human breast cancer cells in vitro, inhibiting tumor growth in mice bearing xenograft tumors. In particular, immune-therapy selectively suppressed breast cancer cell growth but not non-malignant breast cells. Results showed that treatment of breast cancer cells with anti-HERV-K Env monoclonal antibodies induced apoptosis and activated the signaling pathway of TP53, a tumor suppressor protein with a key role in apoptosis and cell senescence [57].

\section{Summary}

According to Hill's criteria of modern epidemiology [99], an association is consistent when results are replicated in studies in different settings using various methods. This signifies that, for a relationship to be causal it has to be consistently found in different studies and different populations. 
The above Italian study [83] raised the possibility that YFV is able to afford protection against melanoma at a very early stage of malignant transformation, perhaps preceding the clinical presentation of melanoma by many years. However, the evidence is based only upon three cases.

Further research appears recommended to confirm and elucidate the temporal pattern of the protection from melanoma attributable to YFV in other geographic areas and larger populations. It appears also appropriate to eliminate/ attenuate the effect of potential confounders such as other vaccinations (namely BCG, vaccinia virus and possibly further vaccinations recommended for travelers to tropical areas) and especially socio-economic status, the latter being a significant risk factor for various malignancies, including melanoma $[100,101]$ and breast cancer $[100,102,103]$.

In view of the above, extending this investigation also to the potential protective effect of YFV on breast cancer appears indicated. Sarcoma, lymphoma, bladder and ovarian cancer should also be considered, as all these malignancies express significant levels of HERV-K Env epitopes [25,57-59,61].

If the above evidence were confirmed new possible pathways for the prevention of cancer could be opened.

Despite monoclonal antibodies against HERV-K Env proteins recently showing interesting results as a potential immunotherapeutic in breast cancer [57], cancer immunotherapy is still considered more complex and less advantageous than cancer immuno-prevention [80,104]. Furthermore, the efficacy of anti-HERV-K immunotherapy in the above study was only evaluated in mice bearing xenograft tumors, hence it should also be tested in breast cancer patients [57]. By contrast, YFV is largely affordable, reliable $[105,106]$ and able to stimulate preventive cellular immunity against cancer, as antibody response is likely not to be the only immune mechanism involved against malignancies [38].

Several pathogens express antigens with an amino acid sequence homologous to the HERV-K-MEL epitope, but either the relevant proteins are not used to arrange the respective vaccines (e.g. tetanus toxoid and acellular pertussis vaccine), or most non-viable preparations are formulated to induce humoral response rather than cellular immunity [38]. Lastly, despite the evidence in favour of vaccinia and BCG vaccinations against the risk of melanoma [38], and the increasing global incidence of tuberculosis, the reintroduction of these two vaccines seems questionable [80].

\footnotetext{
Abbreviations

BCG: Bacille Calmette-Guerin; Cl: Confidence Interval; DNA: Deoxyribonucleic acid; FEBIM: Febrile Infections and Melanoma; HERV: Human Endogenous Retrovirus; HPV: Human Papilloma Virus; LTR: Long Terminal Repeats; OR: Odds Ratio; ORF: Open Reading Frames; RNA: Ribonucleic Acid; tRNA: transfer RNA; RT: Reverse Transcriptase; YFV: Yellow Fever Virus Vaccine; TSV: Time Since Vaccination.
}

\section{Competing interests}

The authors declare that they have no competing interest.

\section{Authors' contributions}

LC and GM conceived the idea and drafted the paper; CS, GP, PV, EW contributed to the drafting of the paper. All authors read and approved the final manuscript.

\section{Funding}

University of Padua.

\section{Author details}

${ }^{1}$ Department of Molecular Medicine, Padua University, Padua, Italy. ${ }^{2}$ Imperial College London, School of Public Health, S. Mary's Campus, London, UK. ${ }^{3}$ Department of Community Medicine, Faculty of Health Sciences, University of Tromsø, Tromsø, Norway. ${ }^{4}$ Department of Research, Cancer Registry of Norway, Oslo, Norway. ${ }^{5}$ Department of Medical Epidemiology and Biostatistics, Karolisnska Institute, Stockholm, Sweden. '5amfundet Folkhälsan, Helsinki, Finland. ${ }^{7} \mathrm{HuGeF}$ Foundation, Turin, Italy.

Received: 29 March 2012 Accepted: 2 December 2012 Published: 3 January 2013

\section{References}

1. Wagner $\mathrm{KH}$, Brath $\mathrm{H}$ : A global view on the development of non communicable diseases. Prev Med 2012, 54(Suppl):S38-41.

2. Bray F, Ren JS, Masuyer E, Ferlay J: Global estimates of cancer prevalence for 27 sites in the adult population in 2008. Int J Cancer 2012, doi:10.1002/ ijc.27711 [Epub ahead of print].

3. Maddams J, Brewster D, Gavin A, Steward J, Elliott J, Utley M, Møller H: Cancer prevalence in the United Kingdom: estimates for 2008. $\mathrm{Br} J$ Cancer 2009, 101(3):541-7.

4. Ries LAG, Melbert D, Krapcho M, Stinchcomb DG, Howlader N, Horner MJ, et al (Eds): SEER Cancer Statistics Review, 1975-2005. Bethesda, MD: National Cancer Institute; 2007. http://seer.cancer.gov/csr/1975_2005. Accessed July 2008.

5. Warren JL, Yabroff KR, Meekins A, et al: Evaluation of trends in the cost of initial cancer treatment. J Natl Cancer Inst 2008, 100(12):888-897.

6. Mariotto AB, Yabroff KB, Shao Y, Feuer EJ, Brown ML: Projections of the cost of cancer care in the United States: 2010-2020. JNCl 2011, 103:117-123.

7. U.S. Census Bureau, Population Division: Interim Projections Consistent With Census 2000 (released March 2004). Washington D.C: U.S. Census Bureau, Population Division; 2008. http://www.census.gov/population/ www/ projections/usinterimproj/. Accessed July 2008.

8. Krone B, Grange JM: Melanoma, Darwinian medicine and the inner world. J Cancer Res Clin Oncol 2010, 136:1787-1794.

9. Rook GA, Dalgleish A: Infection, immunoregulation, and cancer. Immunol Rev 2011, 240:141-159.

10. International Human Genome Sequencing Consortium (IHGSC): Initial sequencing and analysis of the human genome. Nature 2001, 409:860-921.

11. Kazazian HH: Mobile elements: drivers of genome evolution. Science 2004, 303:1626-1632.

12. Griffiths DL: Endogenous retroviruses in the human genome sequence. Genome Biol 2001, 2:1017.1-1017.5.

13. Friedlander A, Patarca R: Endogenous proviruses. Crit Rev Oncog 1999, 10:129-159.

14. Stoye JP: Studies of endogenous retroviruses reveal a continuing evolutionary saga. Nat Rev Microbiol 2012, 10(6):395-406.

15. Bannert N, Kurth R: Retroelements and the human genome: new perspectives on an old relation. Proc Natl Acad Sci USA 2004, 101:14572-14579.

16. Li WH, Gu Z, Wang H, et al: Evolutionary analyses of the human genome. Nature 2001, 409:847-49.

17. Coffin J: Endogenous viruses. In RNA Tumor Viruses. 2nd edition. Edited by Weiss R, Teich N, Varmus H, Coffin J. Cold Spring Harbor, NY: Cold Spring Harbor Press; 1984:1109-1203.

18. Weinberg RA: Origins and roles of endogenous retroviruses. Cell 1980, 22:643-4. 
19. Dolittle WF, Sapienza C: Selfish genes, the phenotype paradigm and genome evolution. Nature 1980, 284:601-3.

20. Orge L, Crick FHC: Selfish DNA. the ultimate parasite. Nature 1980, 284:604-7.

21. Baltimore D: Retroviruses and retrotransposones: the role of reverse transcription in shaping the eukaryotic genome. Cell 1985, 40:481-82

22. Temin HM: Origin and general nature of retroviruses. In The Retroviridae, Vol 1. Edited by Levy JA. New York: Plenum Press; 1992:1-18.

23. Zeyl C, Beli G: Symbiotic DNA in eukaryotic genomes. Trends Ecol Evol 1996, 11:10-5.

24. Boller K, Schönfeld K, Lischer S, Fischer N, HoVmann A, Kurth R, Tönjes RR: Human endogenous retrovirus HERV-K113 is capable of producing intact viral particles. J Gen Virol 2008, 89(Pt 2):567-572.

25. Schiavetti F, Thonnard J, Colau D, Boon T, Coulie PG: A human endogenous retroviral sequence encoding an antigen recognized on melanoma by cytolytic T lymphocytes. Cancer Res 2002, 62(19):5510-6.

26. Flockerzi A, Burkhardt S, Schempp W, Meese E, Mayer J: Human endogenous retrovirus HERV-K14 family: status, variants, evolution and mobilization of other cellular sequences. J Virol 2005, 79:2941-2949.

27. Laufer G, Mayer J, Mueller BF, Mueller-Lantzsch N, Ruprecht K: Analysis of transcribed human endogenous retrovirus $W$ env loci clariWes the origin of multiple sclerosis-associated env sequences. Retrovirology 2009, 6:37-53.

28. Moyes D, Griffithsm DJ, Venables PJ: Insertional polymorphisms. A new lease of life for endogenous retrovirus in human disease. Trends Genet 2007, 2:326-333.

29. Ryan FP: Virolution. New York: Harper Collins; 2009.

30. Gogvadze E, Stukacheva E, Buzdin A, Sverdlov E: Human specific modulation of transcriptional activity provided by endogenous retroviral insertions. J Virol 2009, 83:6098-6105.

31. Kalter SS, Helmke RJ, Heberling RL, Panigel M, Fowler AK, Strickland JE, Hellman A: Brief communication: C-type particles in normal human placentas. J Natl Cancer Inst 1973, 50:1081-1084.

32. Rote NS, Chakrabarti S, Stetzer BP: The role of human endogenous retroviruses in trophoblast diVerentiation and placental development. Placenta 2004, 25:673-683.

33. Larsson E, Andersson G: Beneficial role of human endogenous retroviruses: facts and hypotheses. Scand I Immunol 1998, 48:329-338.

34. Hohenadl C, Germaier H, Walchner M, Hagenhofer M, Herrmann M, Sturzl M, Kind P, Hehlmann R, Erfle V, Leib-Mosch C: Transcriptional activation of endogenous retroviral sequences in human epidermal keratinocytes by UVB irradiation. J Invest Dermatol 1999, 113:587-594.

35. Khan AS, Muller J, Sears JF: Early detection of endogenous retroviruses in chemically induced mouse cells. Virus Res 2001, 79:39-45.

36. Ono M, Kawakami M, Ushikubo H: Stimulation of expression of the human endogenous retrovirus genome by female steroid hormones in human breast cancer cell line T47D. J Virol 1987, 6:2059-2062.

37. Katsumata K, Ikeda H, Sato M, Ishizu A, Kawarada Y, Kato H, Wakisaka A, Koike T, Yoshiki T: Cytokine regulation of env gene expression of human endogenous retrovirus-R in human vascular endothelial cells. Clin Immunol 1999, 93:75-80.

38. Krone B, Kölmel KF, Henz BM, Grange JM: Protection against melanoma by vaccination with Bacille Calmette-Guerin (BCG) and/or vaccinia: an epidemiology-based hypothesis on the nature of a melanoma risk factor and its immunological control. Eur J Cancer 2005, 41(1):104-17.

39. Gimenez J, Montgiraud C, Pichon JP, Bonnaud B, Arsac M, Ruel K, Bouton O, Mallet F: Custom human endogenous retroviruses dedicated microarray identiWes self-induced HERV-W family elements reactivated in testicular cancer upon methylation control. Nucl Acids Res 2010, 38:2229-2246.

40. Stengel S, Fiebig U, Kurth R, Denner J: Regulation of human endogenous retrovirus-K expression in melanomas by $\mathrm{CpG}$ methylation. Genes Chromosom Cancer 2010, 49:401-411.

41. Dolei $\mathrm{A}$, Perron $\mathrm{H}$ : The multiple sclerosis-associated retrovirus and its HERV-W endogenous family: a biological interface between virology, genetics and immunology in human physiology and disease. I Neurovirol 2009, 15:4-13.

42. Gifford $\mathrm{R}$, Tristem M: The evolution distribution and diversity of endogenous retroviruses. Virus Genes 2003, 26:291-315.

43. Belshaw R, Dawson AL, Woolven-Allen J, Redding J, Burt A, Tristem M: Genomewide screening reveals high levels of insertional polymorphism in the human endogenous retrovirus family HERV-K (HML-2): implications for present day activity. J Virol 2005, 79:12507-12514.
44. Tristem M: Identification and characterization of novel human endogenous retrovirus families by phylogenetic screening of the human genome mapping project database. J Virol 2000, 74:3715-30.

45. Löwer R, Lower J, Kurth R: The viruses in all of us: characteristics and biological significance of human endogenous retrovirus sequences. Proc Natl Acad Sci U S A 1996, 93:5177-5184.

46. Sverdlov ED: Retroviruses and primate evolution. Bioessays 2000, 22:161-171.

47. Mayer J, Sauter M, Rácz A, Scherer D, Mueller-Lantzsch N, Meese E: An almost-intact human endogenous retrovirus $\mathrm{K}$ on human chromosome 7. Nat Genet 1999, 21:257-8.

48. Hughes JF, Coffin JM: Human endogenous retroviral elements as indicators of ectopic recombination events in the primate genome. Genetics 2005, 171:1183-1194.

49. Löwer R, Boller K, Hasenmaier B, Korbmacher C, Muller-Lantzsch N, Lower J, Kurth $R$ : Identification of human endogenous retroviruses with complex mRNA expression and particle formation. Proc Natl Acad Sci U S A 1993, 90:4480-4484.

50. Muster T, Waltenberger A, Grassauer A, Hirschl S, Caucig P, Romirer I, Fodinger D, Seppele H, Schanab O, Magin-Lachmann C, Lower R, Jansen B, Pehamberger $\mathrm{H}$, Wolff $\mathrm{K}$ : An endogenous retrovirus derived from human melanoma cells. Cancer Res 2003, 63:8735-8741.

51. Ono M: Molecular cloning and long terminal repeat sequences of human endogenous retrovirus genes related to types $A$ and $B$ retrovirus genes. J Virol 1986, 58(3):937-944.

52. Flockerzi A, Ruggieri A, Frank O, Sauter M, Maldener E, Kopper B, Wullich B, Seifarth W, Müller-Lantzsch N, Leib-Mösch C, Meese E, Mayer J: Expression patterns of transcribed human endogenous retrovirus HERV-K(HML-2) loci in human tissues and the need for a HERV Transcriptome Project. BMC Genomics 2008, 9:354.

53. Sarid R, Gao SJ: Viruses and human cancer: from detection to causality. Cancer Lett 2011, 305(2):218-27.

54. Seifarth W, Baust C, Murr A, Skladny H, Krieg-Schneider F, Blusch J, Werner T, Hehlmann R, Leib-Mosch C: Proviral structure, chromosomal location, and expression of HERV-K-T47D, a novel human endogenous retrovirus derived from T47D particles. J Virol 1998, 72:8384-8391.

55. Büscher K, Trefzer U, Hofmann M, Sterry W, Kurth R, Denner J: Expression of human endogenous retrovirus $\mathrm{K}$ in melanomas and melanoma cell lines. Cancer Res 2005, 65:4172-4180.

56. Contreras-Galindo R, Kaplan MH, Leissner P, Verjat T, Ferlenghi I, Bagnoli F, Giusti F, Dosik MH, Hayes DF, Gitlin SD, Markovitz DM: Human endogenous retrovirus K (HML-2) elements in the plasma of people with lymphoma and breast cancer. J Virol 2008, 82:9329-36.

57. Wang-Johanning F, Rycaj K, Plummer JB, Li M, Yin B, Frerich K, Garza JG, Shen J, Lin K, Yan P, Glynn SA, Dorsey TH, Hunt KK, Ambs S, Johanning GL: Immunotherapeutic potential of anti-human endogenous retrovirus-k envelope protein antibodies in targeting breast tumors. J Natl Cancer Inst 2012, 104(3):189-210.

58. Wang-Johanning F, Radvanyi L, Rycaj K, Plummer JB, Yan P, Jagannadha Sastry K, Piyathilake C, Hunt KK, Johanning GL: Human Endogenous Retrovirus K Triggers an Antigen-Specific Immune Response in Breast Cancer Patients. Cancer Res 2008, 68(14):5869-77.

59. Wang-Johanning F, Frost AR, Jian B, Epp L, Lu DW, Johanning GL: Quantitation of HERV-K env gene expression and splicing in human breast cancer. Oncogene 2003, 22:1528-1535.

60. Wang-Johanning F, Frost AR, Johanning GL, Khazaeli MB, LoBuglio AF, Shaw $D R$, Strong TV: Expression of human endogenous retrovirus $k$ envelope transcripts in human breast cancer. Clin Cancer Res 2001, 7(6):1553-60.

61. Wang-Johanning F, Frost AR, Jian B, Epp L, Lu DW, Johanning GL: Expression of multiple human endogenous retrovirus surface envelope proteins on ovarian cancer. Int J Cancer 2007, 120(1):81-90.

62. Serafino A, Balestrierib E, Pierimarchia P, Matteucci C, Moroni G, Oricchio E, Rasia G, Mastino A, Spadafora C, Garaci E, Sinibaldi Vallebona P: The activation of human endogenous retrovirus K (HERV-K) is implicated in melanoma cell malignant transformation. Exp Cell Res 2009, 315:849-862.

63. Singh S, Kaye S, Gore ME, McClure MO, Bunker CB: The role of human endogenous retroviruses in melanoma. $\mathrm{Br} J$ Dermatol 2009, 161(6):1225-31. Epub 2009 Jul.

64. Herbst H, Sauter M, Mueller-Lantzsch N: Expression of human endogenous retrovirus $\mathrm{K}$ elements in germ cell and trophoblastic tumors. Am J Pathol 1996, 149:1727-1735. 
65. Depil S, Roche C, Dussart P, Prin L: Expression of a human endogenous retrovirus, HERV-K, in the blood cells of leukaemia patients. Leukemia 2002, 16:254-259.

66. Boyd MT, Foley B, Brodsky I: Evidence for copurification of HERV-K-related transcripts and a reverse transcriptase activity in human platelets from patients with essential thrombocythemia. Blood 1990, 90:4022-4030.

67. Ishida T, Obata Y, Ohara N, et al: Identification of the HERV-K gag antigen in prostate cancer by SEREX using autologous patient serum and its immunogenicity. Cancer Immun 2008, 8:15.

68. Ahn K, Kim HS: Structural and quantitative expression analyses of HERV gene family in human tissues. Mol Cells 2009, 28(2):99-103.

69. Schanab O, Humer J, Gleiss A, et al: Expression of human endogenous retrovirus $\mathrm{K}$ is stimulated by ultraviolet radiation in melanoma. Pigment Cell Melanoma Res 2011, 24(4):656-65.

70. Reiche J, Pauli G, Ellerbrok H: Differential expression of human endogenous retrovirus $\mathrm{K}$ transcripts in primary human melanocytes and melanoma cell lines after UV irradiation. Melanoma Res 2010, 20(5):435-40.

71. Gabriel U, Steidler A, Trojan L, et al: Smoking increases transcription of human endogenous retroviruses in a newly established in vitro cell model and in normal urothelium. AIDS Res Hum Retroviruses 2010, 26(8):883-8

72. Contreras-Galindo R, López P, Vélez R, Yamamura Y: HIV-1 infection increases the expression of human endogenous retroviruses type $\mathrm{K}$ (HERV-K) in vitro. AIDS Res Hum Retroviruses 2007, 23(1):116-22.

73. Horsley $\mathrm{V}$, Pavlath GK: NFAT: ubiquitous regulator of cell differentiation and adaptation. J Cell Biol 2002, 156:771-774.

74. Kershaw $\mathrm{MH}, \mathrm{Hsu}$ C, Mondesire W, et al: Immunizatiom against endogenous retroviral tumour-associated antigens. Cancer Res 2001, 61(21):7920-4

75. Sciamanna I, Landriscina M, Pittoggi C, Quirino M, Mearelli C, Beraldi R, Mattei E, Serafino A, Cassano A, Sinibaldi-Vallebona P, Garaci E, Barone C, Spadafora $C$, et al: Inhibition of endogenous reverse transcriptase antagonizes human tumor growth. Oncogene 2005, 24:3923-31.

76. Mangeney M, Pothlichet J, Renard M, et al: Endogenous retrovirus expression is required for murine melanoma tumor growth in vivo. Cancer Res 2005, 65:2588-91.

77. Oricchio E, Sciamanna I, Beraldi R, et al: Distinct roles for LINE-1 and HERV$\mathrm{K}$ retroelements in cell proliferation, differentiation and tumor progression. Oncogene 2007, 26:4226-33.

78. Humer J, Waltenberger A, Grassauer A, et al: Identification of a melanoma marker derived from melanoma-associated endogenous retroviruses. Cancer Res 2006, 66:1658-63.

79. Hahn S, Ugurel S, Hanschmann KM, et al: Serological response to human endogenous retrovirus $\mathrm{K}$ in melanoma patients correlates with survival probability. AIDS Res Hum Retroviruses 2008, 24:717-23.

80. Grange JM, Krone B, Kölmel KF, Mastrangelo G: Can prior vaccinations against certain infections confer protection against developing melanoma? MJA 2009, 191(9):478-479.

81. Koelmel KF, Gefeller O, Haferkamp B: Febrile infections and malignant melanoma: results of a case-control study. Melanoma Res 1992, 2:207-211.

82. Krone B, Kölmel KF, Grange JM, Mastrangelo G, Henz BM, Botev IN, Niin M, Seebacher C, Lambert D, Shafir R, Kokoschka EM, Kleeberg UR, Gefeller O, Pfahlberg A: Impact of vaccinations and infectious diseases on the risk of melanoma-evaluation of an EORTC case-control study. Eur J Cancer 2003, 39(16):2372-8

83. Mastrangelo G, Krone B, Fadda E, Buja A, Grange JM, Rausa G, de Vries E, Koelmel KF: Does yellow fever 17D vaccine protect against melanoma? Vaccine 2009, 27(4):588-91.

84. Hodges-Vazquez M, Wilson JP, Hughes H, Garman P: The yellow fever 17D vaccine and risk of malignant melanoma in the United States military. Vaccine 2012, 30:4476-9.

85. Greenland S, Pearl J, Robins JM: Causal diagrams for epidemiologic research. Epidemiology 1999, 10(1):37-48.

86. De Parseval N, Alkabbani H, Heidmann T: The long terminal repeats of the HERV-H human endogenous retrovirus contain binding sites for transcriptional regulation by the Myb protein. J Gen Virol 1999, 80(Part 4):841-5

87. Lee WJ, Kwun HJ, Kim HS, Jang KL: Activation of the human endogenous retrovirus $\mathrm{W}$ long terminal repeat by herpes simplex virus type 1 immediate early protein 1 . Mol Cells 2003, 15:75-80.
88. Sjottem $E$, Anderssen $\mathrm{S}$, Johansen $\mathrm{T}$ : The promoter activity of long terminal repeats of the HERV-H family of human retrovirus-like elements is critically dependent on Sp1 family proteins interacting with a GC/GT box located immediately 30 to the TATA box. J Virol 1996, 70:188-98.

89. Menendez L, Benigno BB, McDonald JF: L1 and HERV-W retrotransposons are hypomethylated in human ovarian carcinomas. Mol Cancer 2004, 3:12.

90. Florl AR, Lower R, Schmitz-Drager BJ, Schulz WA: DNA methylation and expression of LINE-1 and HERV-K provirus sequences in urothelial and renal cell carcinomas. Br J Cancer 1999, 80:1312-21.

91. Lavie L, Kitova M, Maldener E, Meese E, Mayer J: CpG methylation directly regulates transcriptional activity of the human endogenous retrovirus family HERV-K(HML-2). J Virol 2005, 79:876-83.

92. International Agency for Research on Cancer (IARC): Globocan 2008; Available at: http://globocan.iarc.fr. Accessed in November 2012

93. McPherson $K$, Steel CM, Dixon JM: ABC of breast diseases. Breast cancer epidemiology, risk factors and genetics. BMJ 2000, 321:624-628.

94. Kelsey JL, Bernstein L: Epidemiology and prevention of breast cancer. Annu Rev Public Health 1996, 17:47-67.

95. Hulka BS, Moorman PG: Breast cancer: hormones and other risk factors. Maturitas 2001, 38:103-113. discussion 113-106.

96. Savu A, Potter J, Li S, Yasui Y: Breast cancer and microbial cancer incidence in female populations. Int J Cancer 2008, 123:1094-1099.

97. Ejthadi HD, Martin JH, Junying J, et al: A novel multiplex RT-PCR system detects human endogenous retrovirus-K in breast cancer. Arch Virol 2005, 150(1):177-184.

98. Golan M, Hizi A, Resau JH, et al: Human endogenous retrovirus (HERV-K) reverse transcriptase as a breast cancer prognostic marker. Neoplasia 2008, 10(6):521-533.

99. Hill $A B$ : The environment and disease: association or causation? Proc $R$ Med Soc 1965, 58:295-300

100. Shack L, Jordan C, Thomson ST, Mak V, Møller H: Variation in incidence of breast, lung and cervical cancer and malignant melanoma of skin by socioeconomic group in England. BMC Cancer 2008, 8:271.

101. Markovic SN, Erickson LA, Rao RD, Weenig RH, Pockaj BA, Bardia A, et al: Malignant melanoma in the 21st century. Part 1. Epidemiology, risk factors, screening, prevention, and diagnosis. Mayo Clin Proc 2007, $82: 364-80$

102. Yost K, Perkins C, Cohen R, Morris C, Wright W: Socioeconomic status and breast cancer incidence in California for different race/ethnic groups. Cancer Causes Control 2011, 12:703-711.

103. Pukkala $E$, Weiderpass E: Time trends in socio-economic differences in incidence rates of cancers of the breast and female genital organs (Finland, 1971-1995). Int J Cancer 1999, 81:56-61.

104. G F, PL L, P M, Colombo MP: Immunoprevention of Cancer: Is the Time Ripe? Cancer Res 2000, 60:2571-2575.

105. Roukens AH, Visser LG: Yellow fever vaccine: past, present and future. Expert Opin Biol Ther 2008, 8:1787-95.

106. Pulendran B: Learning immunology from the yellow fever vaccine: innate immunity to systems vaccinology. Nat Rev Immunol 2009, 9(10):741-7.

doi:10.1186/1471-2407-13-4

Cite this article as: Cegolon et al:: Human endogenous retroviruses and cancer prevention: evidence and prospects. BMC Cancer 2013 13:4.

\section{Submit your next manuscript to BioMed Central and take full advantage of:}

- Convenient online submission

- Thorough peer review

- No space constraints or color figure charges

- Immediate publication on acceptance

- Inclusion in PubMed, CAS, Scopus and Google Scholar

- Research which is freely available for redistribution 